\title{
IDEOLOGÍA Y CONCEPTO DEL MATRIMONIO ${ }^{1}$
}

\author{
Jorge Adame Goddard \\ Instituto de Investiga ciones] uńdicas \\ Universidad Nacional Autónoma de México
}

\section{Resumen}

La ideología, tantas veces instrumento de lucha al margen del esfuerzo por la comprensión, forma parte del discurso propio de los debates; el concepto nos remite a lo que se mantiene idéntico en sus elementos esenciales, siendo la elaboración de conceptos y su posterior relación y organización en un sistema lo propio del pensamiento científico. El legislador históricamente ha venido disponiendo sobre el concepto de matrimonio, casi como puede el propietario disponer de una cosa, en una clara manifestación

- Palabras clave: Ideología; Concepto científico; Matrimonio; Evolución legislativa; México de lo que es el pensamiento ideológico, un pensamiento sujeto a negociación. Frente a la ideologización del matrimonio, el autor propone recuperar su esencia.

- Keywords: Ideology; Scientific concept; Marriage; Legislative development; México

\begin{abstract}
Ideology indicates debate, concept refers to development of scientific systems. In contrast to historical legislative role, author proposes to give up ideological components and sharpe the focus on the marriage conceptual essence.
\end{abstract}

I. Introducción - II. La ideología del matrimonio - III. El concepto del matrimonio - IV. Conclusión

${ }^{1}$ La mesa en la que fue pronunciada esta conferencia fue presentada y moderada por el Prof. Dr. José Ramón Narváez Hernández, Profesor del Posgrado en Derecho de la Universidad Nacional Autónoma de México e Instituto de Investigaciones Jurisprudenciales y de Promoción y Difusión de la Ética Judicial de la Suprema Corte de Justicia de la Nación, representante del partner internacional en México y coordinador de la actividad en aquel país. 


\section{INTRODUCCIÓN}

Ideología y concepto son dos formas diferentes de explicar la realidad. La ideología, de acuerdo con la definición que da Karl Mannheim en su conocida obra Ideología y Utopía $a^{2}$, es una explicación o interpretación de la realidad conformada para favorecer o defender determinados intereses económicos o políticos. Es el discurso propio de los debates políticos, de las negociaciones, en las que se puede ceder y modificar las ideas con tal de obtener determinadas ventajas. No quiero esto decir que todo el pensamiento ideológico es sofisma, engaño, pero su característica primordial no es el tratar de comprender la realidad tal cual es, sino de presentarla de forma que resulte conveniente o ventajosa para determinadas posiciones.

Cuando se habla del concepto o noción de alguna cosa se pretende, aunque no siempre se logre, hacer una presentación intelectual, una abstracción, lo más fiel posible de lo que esa cosa es. A veces se objeta que las cosas no tienen una realidad fija, sino cambiante, de modo que pueden ser de una manera y luego lo son de otra. Pero esta misma objeción supone la permanencia de la cosa que puede asumir distintas formas o modos de ser y seguir siendo, no obstante, la misma cosa.

Esta permanencia de las cosas, a pesar de su incesante cambio, es el presupuesto de todas las ciencias naturales que se ocupan de los seres inanimados o de los seres vivos. Se pueden, por ejemplo, clasificar los elementos de la materia, porque se presupone que de alguna manera son permanentes, aunque puede haber múltiples combinaciones entre ellos y alteraciones de cada uno; se pueden clasificar las especies biológicas, sin negar la mutación que ha habido entre ellas, porque hay una cierta permanencia de las mismas.

Algo semejante sucede en el ámbito de la vida social: hay muchas realidades que, no obstante la mutabilidad de la historia humana, se mantienen idénticas en sus rasgos esenciales, por ejemplo la relación de intercambio de una cosa por una cantidad de dinero, o la relación de dos o más personas para procurar un fin común que a todas beneficie, o la necesidad, en todo grupo humano, de un orden coactivo y de un gobierno. Y así como las ciencias naturales elaboran conceptos que pretenden ser representaciones intelectuales o abstracciones de una determinada realidad, las ciencias sociales y humanas elaboran conceptos acerca de la realidad del ser humano y de su vida comunitaria, como los conceptos de compraventa, asociación, poder político que reflejan esas realidades permanentes.

La elaboración de conceptos y su posterior relación y organización en un sistema es lo propio del pensamiento científico. Quien hace ciencia tiene una posición muy diferente del ideólogo; al científico lo que le interesa es el conocimiento de la realidad tal cual es.

\footnotetext{
2 MANNHEIM, Karl, Ideología y utopía: una introducción a la sociología del conocimiento, trad. por Eloy Terrón, Madrid, 1966.
} 
Respecto del matrimonio, se pueden hacer esas dos explicaciones, una ideológica y otra conceptual. Se puede explicar ideológicamente como el resultado de una determinada posición política o económica que impone una imagen del matrimonio, por medios legislativos, con apoyos económicos y de los medios de comunicación masiva. Se puede explicar conceptualmente lo que es el matrimonio a partir de la observación de lo que hay de permanente en esa relación humana que se suele llamar matrimonio. Podría haber una tercera explicación en esta materia, como en muchas otras, que sería la explicación sociológica por la cual se indica cómo es que de hecho se vive, en un determinado grupo social, esa relación llamada matrimonio.

La posición ideológica es la intelectualmente menos defendible; es más arma de lucha, que esfuerzo de comprensión. La explicación conceptual es quizá la más difícil de alcanzar porque supone, no solo la atenta observación de la realidad, sino además la discriminación entre lo permanente y lo accidental; esto es, el esfuerzo por precisar las notas esenciales o propiedades de cada cosa. La explicación sociológica se refiere a la medición de lo que ocurre, de modo que refleja la realidad actual; tiene la dificultad de que debe generalizar los resultados obtenidos a través de la observación de poco casos (siempre serán pocos, aunque sean miles), como si fueran representativos de lo que ocurre en la totalidad del grupo analizado, y esto genera un margen de error e incertidumbre.

La explicación conceptual y la sociológica por sí mismas no se contradicen, sino que se complementan. La primera tiende a lo permanente, la segunda a lo actual; la primera indica lo que es posible, la segunda, lo que de hecho ocurre. Todo intento serio de reforma social debe tener en cuenta ambas conclusiones, de modo que se oriente lo actual hacia lo mejor posible, y no que se reduzca lo posible a lo actual, renunciando a lo mejor; ni que se oriente lo actual hacia lo imposible, lo que sería gran insensatez.

En este trabajo no me referiré a esa explicación sociológica del matrimonio, porque mi intención es demostrar cómo una concepción ideológica del matrimonio se ha venido imponiendo por vía legislativa, hasta el punto de prácticamente afirmarse que el matrimonio no tiene una realidad propia, sino que es lo que los legisladores deciden que sea. Y, por otra parte, intento proponer un concepto de matrimonio inferido a partir de la realidad de la capacidad que tiene el ser humano de amar al prójimo como a sí mismo y de las relaciones que establece a partir de ella.

\section{LA IDEOLOGÍA DEL MATRIMONIO}

La ideologización del matrimonio a la que me quiero referir comienza como resultado de la Revolución Francesa que, en su afán de establecer la independencia entre el poder político y la Iglesia, lleva al poder político a reclamar, como una atribución propia y soberana, el poder de legislar acerca del matrimonio sin ninguna limitación. Es un proceso que se ha vivido en los países que recibieron el influjo de dicha revolución, y seguramente con diversos matices en cada uno. En este trabajo únicamente me referiré a cómo se produce esta ideologización del matrimonio en la 
legislación civil mexicana, presuponiendo que algo semejante habrá ocurrido en otros países.

El punto de partida en México fue la Ley del matrimonio civil del 3 de julio de $1859^{3}$, una de las llamadas “leyes de Reforma”. En los considerandos de esta ley, se dice que el Estado da por terminada la delegación de potestad que había hecho a favor de la Iglesia para que ésta regulara el matrimonio, y que reasume "todo el ejercicio del poder" en esta materia, por lo que cuidará de que "un contrato tan importante como el matrimonio, se celebre con todas las formalidades que juzgue convenientes a su validez y firmeza”.

Cuando el Estado afirma que tiene todo el poder para regular el matrimonio se entiende que el Estado tiene el poder de decidir qué es el matrimonio, y así lo entendieron los legisladores. Es evidente que la posición que asume el Estado liberal frente al matrimonio es una posición política, una manera de afirmar la independencia del poder político frente a la Iglesia. Y desde esta posición política, es de donde partirá la ideologización del matrimonio, considerado ya, no como una realidad independiente, sino como una materia de la cual disponen los legisladores, según sea la conveniencia política del momento. En un principio, las definiciones legales del matrimonio serán más o menos conformes con la noción o concepto que la misma sociedad tenía del mismo, pero poco a poco irán introduciendo novedades "revolucionarias".

En esta ley de 1859 ya se da una definición del matrimonio. Dice, en su artículo primero, que es "un contrato civil que se contrae lícita y válidamente ante la autoridad civil”, y señala que para ser válido se requiere que los contrayentes expresen libremente su consentimiento y que cumplan "las formalidades que establece esta ley”. Señala además que se contrae "por un solo hombre con una sola mujer” (art. 3) y que es indisoluble (art. 4). Además prescribía que el oficial del Registro Civil encargado, una vez cumplidos los trámites matrimoniales, haría una exhortación moral a los contrayentes, leyéndoles un texto, conocido como la «epístola de Melchor Ocampo», donde se les recordaban sus deberes morales.

Después de la guerra civil entre el partido liberal y el partido conservador y del intento frustrado del segundo imperio mexicano, el partido liberal, en 1867, quedó dueño del poder político. Entonces, para consolidar los principios liberales, se hizo una reforma de la constitución vigente, la llamada Constitución de 1857, para incorporarle el contenido de las leyes de reforma, entre otras la del matrimonio civil. Se estableció así, en la reforma constitucional de 1873, (art. 130, tercer párrafo), la afirmación de que "el matrimonio es un contrato civil", de la "exclusiva competencia” de las autoridades civiles y cuyas “fuerza y validez” determinarán las leyes civiles. Quedó así establecido, como un principio constitucional, que el legislador podrá decidir libremente sobre "la fuerza y validez" del matrimonio, esto es sobre qué unión es válida para ser considerada matrimonio y que efectos tiene esa unión.

${ }^{3}$ La ley se puede consultar en Derechos del Pueblo Mexicano, $4^{\text {a }}$ ed., México, 1994, T. XII, p. 1090. 
Unos años antes, en 1870 se había publicado el primer Código civil para regir en el Distrito Federal, que contenía una definición del matrimonio (art. 159), que decía: "El matrimonio es la sociedad legítima de un solo hombre y una sola mujer, que se unen con vínculo indisoluble para perpetuar la especie y ayudarse a llevar el peso de la vida”. Es una definición que correspondía al concepto de matrimonio que tenía la sociedad mexicana. Cuando se publicó un nuevo código el año 1884, después de que se había establecido en la constitución que el matrimonio era un "contrato”, el código nuevo no cambió la definición del código de 1870 y siguió definiéndolo (art. 155) como una "sociedad legítima”.

Hasta este momento, la intervención de los legisladores no había modificado la concepción tradicional del matrimonio, pero ya se había afirmado en la constitución el principio de que los legisladores disponen del matrimonio.

El año de 1914 se va a introducir un cambio “revolucionario”. Entonces gobernaba, con facultades extraordinarias, el general Venustiano Carranza, quien expide dos decretos $^{4}$ con el fin de modificar la legislación vigente, que contemplaba el matrimonio como una unión que solo podía disolverse con la muerte de uno de los cónyuges, y establecer que el matrimonio podía disolverse por mutuo acuerdo de los cónyuges, o por alguna falta grave de uno de ellos, y quedar entonces ambos con la posibilidad de contraer un nuevo matrimonio. La motivación para expedir este decreto aparentemente había sido el propio plan de la revolución constitucionalista. El plan original, llamado Plan de Guadalupe, firmado el 26 de marzo de 1913, nada decía acerca de reformar la legislación sobre el matrimonio, pero en unas adiciones a ese plan, aprobadas el 12 de diciembre de 1914, se decía que era necesario revisar las "leyes relativas al matrimonio y al estado civil". Se reforma entonces el matrimonio, según la versión oficial, por un compromiso político, lo cual demuestra que se trata de una reforma ideológica, que responde a determinados intereses y posiciones políticas.

La modificación del matrimonio en el sentido de ser una unión disoluble se confirma con la expedición de una nueva ley, llamada Ley de relaciones familiares ${ }^{5}$, expedida el año de 1917. En la exposición de motivos de esa ley, se muestra su carácter ideológico: ahí se dice que las reformas políticas y sociales que pretende la revolución "no pueden implantarse debidamente sin las consiguientes reformas a todas las demás instituciones sociales, y muy especialmente a las familias”, de modo que la reforma del matrimonio obedece a los intereses de la revolución. La ley da (art. 13) una nueva definición del matrimonio: "es un contrato civil entre un solo hombre y una sola mujer, que se unen con vínculo disoluble para perpetuar la especie y ayudarse a llevar el peso de la vida”. Ahora el legislador ha decidido que

${ }^{4}$ Uno firmado el 29 de diciembre de 1914, que modifica la legislación federal del matrimonio, y otro del 29 de enero de 1915 que modifica el código civil del Distrito Federal. Pueden verse en Leyes complementarias del Código Civil, Pallares E., edit., México, 1920, pp. 421-426.

${ }^{5}$ Puede verse el texto completo de la ley y su exposición de motivos en Código Civil vigente del Distrito y territorios Federales, anotado y concordado por Manuel Andrade, México, 1931, pp. 115 y ss. 
el matrimonio no es una "sociedad legítima”, sino un "contrato civil” y que genera, ya no un "vínculo indisoluble”, sino un "vínculo disoluble”. El legislador lo puede todo en esta materia, pues como dice la constitución, de él dependen la "validez y la fuerza” del matrimonio.

El año de 1928, once años después de la Ley de relaciones familiares, se expide un nuevo Código civil para el Distrito Federal, que vuelve a cambiar la concepción del matrimonio. Lo primero que se observa en este código es que ya no hay una definición de lo que es el matrimonio. En algunos artículos se dice, incidentalmente, que es un contrato, pero ya no hay una indicación directa de cuáles son sus fines; éstos se mencionan en un artículo (el 182), que dice no es válida cualquier condición pactada que resultara “contraria a la perpetuación de la especie y la ayuda mutua”, pero en ningún lado se afirma directamente que estos son los fines esenciales del matrimonio, como lo decían los códigos anteriores y aun la ley de 1917. Los cambios que se habían iniciado en esa ley para establecer la igualdad entre el varón y la mujer, se continúan en este código, pero se sigue manteniendo la idea de que corresponde al varón el sostenimiento económico de la familia y a la mujer la administración del hogar. En materia de divorcio, que en la ley anterior se consideraba como una excepción en pocos casos, el código aumenta las causas del divorcio necesario por resolución judicial, e introduce una forma simplificada de divorcio, cuando no hay hijos, llamada "divorcio administrativo", pues no es necesaria la intervención de un juez. Además establece que se reconocerán ciertos efectos jurídicos al concubinato, o unión de hecho no formalizada ante el oficial del registro civil, con lo cual los autores comienzan a afirmar que el matrimonio ya no era, como lo decía aquella “epístola de Melchor Ocampo”, el único medio moral de fundar una familia; ahora se podía fundar a partir del concubinato.

Las modificaciones introducidas por este código son todavía reflejo o consecuencia de los anhelos revolucionarios de igualdad y libertad que tienden a concretarse en el matrimonio como igualdad entre los esposos y libertad para disolver el vínculo conyugal.

A partir del año 1974, se vienen haciendo nuevas reformas, que tienen ahora la característica de ser impulsadas por organismos internacionales. A fines de ese año, y en sintonía con el Año Internacional de la Mujer que había proclamado la Asamblea de Naciones Unidas para el año 1975, se modificó la Constitución para establecer la igualdad entre el varón y la mujer, así como el derecho de "toda persona” a decidir sobre el número y espaciamiento de los hijos. De este cambio constitucional, se derivó una reforma del Código civil, en el cual se estableció el mismo principio de la igualdad entre los esposos y se suprimió la indicación de que correspondía al varón el sostenimiento económico y a la mujer la administración del hogar. Por sucesivas reformas $(1983,1994,1997)$ se prosigue en la línea de igualación del papel de los esposos y de ampliar el número de las causales de divorcio, que se llega a admitir por el solo hecho de la separación física durante dos años o más, sin necesidad de probar ninguna conducta culpable, y también en los casos de "violencia familiar", entendida en un sentido muy amplio que comprende “el uso de la fuerza física o moral o las omisiones graves”. 
El año 2000, cuando se reconoce cierta soberanía legislativa al Distrito Federal, antes las leyes que lo regían tenían que ser aprobadas por el Congreso General, se expide un nuevo código para el Distrito Federal en el que se radicaliza la evolución que venía teniendo el matrimonio. Se da un nuevo concepto de matrimonio (art. 146), que dice: "Matrimonio es la unión libre de un hombre y una mujer para realizar la comunidad de vida, en donde ambos se procuran respeto, igualdad y ayuda mutua con la posibilidad de procrear hijos de manera libre, responsable e informada. Debe celebrarse ante el Juez del Registro Civil y con las formalidades que esta ley exige”. El matrimonio ya no es "sociedad legítima”, ni "contrato civil”, como lo afirmaban los códigos anteriores; ahora es "unión libre" que, sin embargo, debe revestir ciertas formalidades. El fin del matrimonio es hacer una "comunidad de vida” donde ambos, en un plano de igualdad, se respeten y ayuden. Ha desaparecido la idea de un vínculo jurídico entre los cónyuges, que todavía se mencionaba expresamente en la ley de relaciones familiares, e implícitamente en la definición del matrimonio como "contrato civil"; ahora es simplemente "unión libre” aunque genera ciertas consecuencias jurídicas. La procreación deja de considerarse como un fin esencial del matrimonio, para ser vista simplemente como una posibilidad o derecho que tienen los cónyuges.

El 3 de octubre del año 2008 se publica una nueva reforma en la que se extraen consecuencias de lo que significa que el matrimonio es "unión libre". La reforma establece (art. 266) que cualquiera de los cónyuges puede reclamar el divorcio ante el juez "manifestando su voluntad de no querer continuar con el matrimonio, sin que se requiera señalar la causa por la cual se solicita”. Si el matrimonio es "unión libre”, es decir sin compromiso, es lógico que termine por la sola revocación de la voluntad de uno de vivir con el otro.

Poco más de un año después se publica otra reforma, que es consecuencia de haber suprimido la procreación como uno de los fines esenciales del matrimonio, y haberla reducido a una mera posibilidad o derecho subjetivo de los que viven en unión libre. El 29 de diciembre de 2009 se publica la reforma que modifica la definición del matrimonio para aceptar como tal la unión entre personas del mismo sexo. La definición dice ahora que el matrimonio es la "unión libre de dos personas” y, para no dejar dudas, se eliminó la referencia a la “posibilidad de procrear hijos”.

Es impresionante cuánto ha cambiado la concepción legislativa del matrimonio en tan solo ciento cincuenta años. En 1859 los legisladores se arrogaron el derecho de definir qué es el matrimonio. Primero dicen, lo que la comunidad entendía, que el matrimonio es una sociedad o unión legítima, entre un solo varón y una sola mujer, para ayudarse mutuamente y procrear hijos, que genera un vínculo jurídico indisoluble (códigos de 1870 y 1884). Luego dicen que no es una sociedad legítima, sino un contrato civil, y que produce un vínculo disoluble por divorcio voluntario o judicial (ley de relaciones familiares de 1917). Prosiguen omitiendo la referencia explícita a los fines del matrimonio, favoreciendo la equiparación de los papeles de los esposos, y facilitando el divorcio, que, en ciertos casos, puede hacerse sin necesidad los jueces (código de 1928 y sus reformas). Concluyen señalando que el matrimonio es “unión libre” con la posibilidad de procrear (código de 2000), que se puede disolver por la sola voluntad de uno de los contrayentes (repudio unilateral) 
(reforma de 2008), y que se puede contraer entre personas del mismo sexo porque la procreación ya no es un fin del matrimonio (reforma de 2009).

Toda esta evolución depende simplemente de la idea de que los legisladores tienen poder para definir lo que es el matrimonio, de modo que éste resulta siendo lo que ellos quieren. Esta concepción del poder del legislador para definir a su gusto el matrimonio se esgrimió como argumento en la sentencia de la Suprema Corte de Justicia de México que convalidó la reforma que admitió el matrimonio entre personas del mismo sexo; dice la sentencia (§ 242) que el matrimonio no es un “concepto petrificado" "inmutable” o "indisponible”. El legislador puede entonces disponer del concepto de matrimonio, como puede el propietario disponer de una cosa. Esta es una clara manifestación de lo que es el pensamiento ideológico, un pensamiento del que se dispone a gusto de quien lo emite; un pensamiento sujeto a negociación, un pensamiento que favorecerá al mejor postor. No sería extraño que en unos años más se reforme la definición del matrimonio para que diga que es la "unión libre de dos o más personas”.

La definición legal del matrimonio no puede ser tomada en serio si se quiere conocer qué es el matrimonio. Ciertamente que los abogados y los jueces tendrán que contar con ella, pero no refleja lo que el matrimonio es, sino las preocupaciones e intereses políticos que se han impuesto. Para conocer lo que es el matrimonio hay que volver los ojos a esa noble capacidad que tiene el ser humano, varón o mujer, de amar a otro como a sí mismo. Ese es el punto de partida de la siguiente parte de este escrito.

\section{EL CONCEPTO DEL MATRIMONIO}

El matrimonio, en su aspecto más evidente, es una relación humana entre dos personas, libremente asumida. Esta relación se distingue de otras, como de una compraventa o de una asociación mercantil, en que es una relación personal, que se establece por razón de las personas, y no por razón de un determinado bien. Se puede, por lo tanto, avanzar en la determinación de lo que es el matrimonio afirmando que se trata de una relación personal o afectiva, distinta por lo tanto de las relaciones patrimoniales.

El matrimonio es una relación afectiva libremente asumida, pero hay otras formas de relación afectiva libremente asumidas, como la amistad, ¿cómo se distingue de ella?

Me parece que, siguiendo a Aristóteles ${ }^{6}$, todas las formas de relación personal se pueden llamar amistad. Actualmente se suele llamar amistad o amigos únicamente a las personas, generalmente no parientes, con los que se tiene una relación afectiva; pero también se acepta que puede haber amistad entre padres e hijos o, más

${ }^{6}$ Aristóteles, Ética Nicomaquea 8,2 (p. 103) (En lo sucesivo Ética). Cito la traducción al Español hecha por Antonio Gómez Robledo (México, Porrúa, 1967; cito la 19a edición -en realidad reimpresión- del año 2000) que, no obstante la desventaja de no tener los renglones numerados para poder citarla con más precisión, tiene el gran mérito de ser una traducción legible y que transmite el sentido del texto, además de ser fácilmente consultable. La parte de la Ética que trata de la amistad son los libros 8 y 9. 
comúnmente, entre hermanos, y también entre esposos. Entendiendo la amistad en el sentido amplio que usa Aristóteles, el de relación afectiva libremente querida entre dos personas, bien se puede hablar de la amistad paterna, de la amistad filial, de la amistad fraterna o de la amistad conyugal.

La amistad es una relación entre dos personas e implica necesariamente reciprocidad. Cuando se habla del amor de una persona por otra, se indica que una ama y la otra es amada. En cambio, cuando se habla de amistad se indica que las dos personas recíprocamente se aman.

El matrimonio se ha entendido comúnmente como una amistad entre varón y mujer. La amistad entre ellos es una amistad entre dos que son diferentes por razón de su sexo. Como seres humanos tienen la misma naturaleza, igual dignidad, y no se puede hablar de que uno sea superior al otro. Pero es una realidad evidente que el varón y la mujer son diferentes en la conformación de su cuerpo (anatomía), en el funcionamiento del mismo (fisiología), en sus sensaciones y emociones (psicología) y en sus modos de entender y de querer (hábitos intelectuales y hábitos volitivos). Es cierto que cada persona tiene que asumir y desarrollar su propia sexualidad, pero este esfuerzo parte de la aceptación de la realidad del propio cuerpo. La amistad entre varón y mujer es una amistad hacia el otro que es diferente de mi, y no hacia uno igual a mi, es por eso es una amistad abierta a la diferencia.

La diferencia real entre varón y mujer, hace que su amistad sea complementaria, pues cada uno recibe del otro lo que uno mismo no tiene. El signo más evidente de esa complementariedad es la fecundidad biológica: sólo de la unión entre varón y mujer resulta la procreación, y aún cuando se emplean métodos de fecundación artificial, tiene que hacerse a partir de un gameto masculino y otro femenino. La fecundidad de la amistad entre varón y mujer no se limita a la procreación, pues abarca la totalidad de los diferentes aspectos de la vida humana, ya que en cada uno de ellos se manifiesta la diferencia y complementariedad de los sexos. El ser humano perfecto, es decir en la máxima realización de todas sus capacidades, no es el varón o la mujer aislados, sino el varón y la mujer recíprocamente unidos y complementados.

La amistad entre dos varones o entre dos mujeres, con todo lo bueno que puede haber en ella, no es equiparable al matrimonio, porque no es una amistad entre diferentes, sino entre iguales, por lo que carece de la fecundidad y complementariedad propia de la amistad entre varón y mujer.

Se puede ahora dar un paso más en la delimitación del concepto de matrimonio, afirmando que es una forma de amistad entre varón y mujer, pero todavía se requiere precisar qué tipo de amistad es la propia del matrimonio.

Aristóteles señala que toda amistad se establece en relación a un bien que aprovecha a ambas personas, por lo que las amistades se distinguen según sea el tipo de bien al que ambas aspiran. Distingue tres tipos de amistad: útil, placentera y honesta. 
La amistad útil es la que se contrae para la obtención de un bien útil para ambas partes, como puede ser la amistad entre comerciantes, entre aliados políticos, entre los trabajadores en una misma obra, etcétera. Esta amistad supone un cierto afecto, o aprecio personal, entre quienes se relacionan, pero es un aprecio que depende de la utilidad que recíprocamente se proporcionan, y que termina cuanto la utilidad cesa.

La amistad placentera es la que une a las personas por razón del placer que recíprocamente se proporcionan. Es la amistad típica de quienes se reúnen para pasarla bien en una fiesta o reunión o simplemente para charlar. Es el tipo de relación a la que hoy suele dársele por lo general el nombre de amistad. Implica al reconocimiento de ciertas cualidades del amigo que resultan placenteras, como su conversación, simpatía, apariencia física, ingenio y otras por el estilo, que provocan que se le tenga afecto. Es una amistad que tiene una base más amplia que la amistad meramente útil, pero, como depende de un bien parcial, el placer de la compañía, termina cuando ese bien se extingue, por ejemplo a causa de una enfermedad.

Finalmente, la amistad honesta, es aquella que une a las personas por razón de la persona misma del amigo, que se considera un bien en sí mismo, o bien honesto, independientemente de la utilidad o placer que proporcione. El afecto que genera está amistad está relacionado con la totalidad de la persona del amigo, y esto genera dos características propias o exclusivas de esta amistad. Es una amistad que procura el bien integral o total del amigo, no solo su bien económico, su salud o cualquier otro bien parcial; el amigo que quiere honestamente quiere el bien total de su amigo, quiere que sea él mismo en toda su plenitud posible. Es además una amistad que no termina más que con la muerte del amigo, y por lo tanto perdura, aunque el amigo se halle en desgracia. Esto es lo que se dice comúnmente con la frase de que los verdaderos amigos (los que tiene amistad honesta) se conocen en la desgracia.

Estas tres formas de amistad no son excluyentes. De hecho sucede que la amistad útil se combina con la amistad placentera, y que la amistad honesta comprende el placer y la utilidad. De cualquier modo, la distinción de estas tres formas de amistad corresponde a la realidad de los afectos humanos, como cualquier persona puede experimentarlo en sí misma.

La amistad entre varón y mujer puede darse en esos tres niveles. Puede haber entre ellos una amistad útil, por la que se hacen recíprocamente ciertos servicios para beneficio de ambos. O puede ser una amistad en el plano de lo útil y lo placentero, de modo que disfrutan de su compañía, con o sin unión sexual, y se ayudan recíprocamente, pero cada uno vive por su cuenta. Pueden dar un paso más en esta relación si toman la decisión de vivir juntos, y entonces se intensifica el placer y la ayuda (o el disgusto y los problemas) que se proporcionan, pero no por el hecho de vivir juntos superan el nivel de lo útil y placentero; otro paso en esa relación sería la decisión de «tener» hijos, que se reciben, más como un bien del cual pueden disfrutar, que como el resultado de una entrega y compromiso de por vida, que no hay entre ellos.

También puede darse una amistad honesta entre varón y mujer acompañada de la decisión de vivir juntos y compartir su vida. En esta amistad, el varón y la mujer 
ponen recíprocamente todas sus facultades y bienes, incluida su propia sexualidad y capacidad procreativa, al servicio del otro, al que consideran un bien por sí mismo, un bien del mismo valor que uno mismo. Cada uno se vuelve un bien para el otro, y por eso constituyen una unidad que es superior al varón o a la mujer individual o aisladamente considerada. Cada uno quiere el bien del otro como quiere su propio bien, y por eso es en esta amistad donde se cumple plenamente la llamada «regla de oro», por haber sido reconocida en todas las culturas, que dice «ama al prójimo como a ti mismo».

Esta amistad honesta que es, por principio, entrega total por toda la vida, incluye necesariamente la apertura a la procreación y la prolongación de esa amistad hacia los hijos, a quienes los padres se entregan, como entre sí mismos, totalmente y por toda la vida.

Las tres formas de amistad pueden darse en la relación entre varón y mujer. ¿Cuál de ellas puede considerarse matrimonio? Si se acepta que todo ser humano, por la dignidad inherente a su persona, debe ser amado como un bien en sí mismo, y no como un medio para la obtención de ciertos fines, se podrá concluir que la unión entre varón y mujer plenamente conforme con esa dignidad de la persona humana, es la amistad honesta, y por eso sólo a ella debería denominarse matrimonio. La relación de varón y mujer a nivel de lo útil y placentero, con la decisión de vivir juntos y tener hijos, parece matrimonio, o es camino para hacer un matrimonio, que sólo se lograra cuando ambos, no basta uno solo, decidan entregarse al otro totalmente, por toda la vida.

Volviendo al concepto del matrimonio, se puede ahora afirmar que es una amistad honesta entre varón y mujer, es decir entrega recíproca total de uno al otro por toda la vida, que han decidido vivir juntos y procrear hijos o, como se dice comúnmente, formar una familia.

Hay otro elemento de la realidad del matrimonio que falta por considerar, que es su publicidad. El matrimonio suele realizarse en forma pública, mediante una fiesta social y un reconocimiento de parte de la comunidad política y de la comunidad religiosa. Este reconocimiento público es un elemento indispensable del matrimonio, porque resulta que éste es el fundamento de la continuidad y supervivencia de la comunidad. Esto, en dos sentidos: el más evidente es que del matrimonio nacen los nuevos integrantes de la comunidad; pero, no menos importante, es que el matrimonio, en cuanto amistad honesta, es el medio adecuado para la educación de los hijos y para la difusión, entre toda la comunidad, de esa forma de amor recíproco que está por encima de la utilidad y del placer; si en una comunidad se pierde esa forma de amistad, la vida social se reduce a la competencia y al predominio del más fuerte; por eso la misma calidad humana de la vida comunitaria depende de la existencia de matrimonios y familias en que se viva la amistad honesta que, se difunde en la vida comunitaria, como amistad solidaria (o solidaridad), especialmente con los más débiles.

La publicidad del matrimonio tiene la consecuencia de generar un vínculo jurídico entre el varón y la mujer. El matrimonio comienza siendo amistad honesta, junto con 
la decisión de entrega recíproca y total por toda la vida. Cuando se manifiesta públicamente la voluntad que tienen el varón y la mujer, se genera un vínculo o alianza entre ellos, que está jurídicamente sancionado. No cambia la naturaleza del matrimonio, sigue siendo amistad honesta, pero adquiere un sello o garantía que es el vínculo jurídico, es decir la posibilidad de que los cónyuges entre sí, se exijan por justicia lo que se deben por amistad. Esta alianza o reforzamiento jurídico del matrimonio tiene su razón de ser en la debilidad propia del ser humano, que fácilmente incumple lo que promete.

Finalmente, en esta reflexión sobre lo que es el matrimonio, hay que considerar que no es un estado pasajero, no es un acto, como podría ser la celebración social o la inscripción en el registro público. El matrimonio es esencialmente amistad honesta entre varón y mujer, con el compromiso, públicamente asumido, de vivir juntos y formar una familia, que tiene como resultado natural la unión permanente entre varón y mujer, con o sin familia. Desde este punto de vista, el matrimonio es unión, comunidad de vida, y el afecto entre los esposos o amistad conyugal no es una emoción fugaz, sino disposición estable de su voluntad o virtud.

\section{CONCLUSIÓN}

Ante la ideologización del matrimonio que lo ha reducido al capricho del legislador: el matrimonio es lo que el legislador dice que es, es necesario recuperar lo que constituye la esencia del matrimonio: la amistad honesta entre varón y mujer, con el compromiso públicamente asumido, de vivir juntos y formar una familia, de lo cual resulta la unión de ambos por toda la vida y la conversión de su afecto en virtud estable.

Al legislador no le corresponde definir qué es el matrimonio, ni cuáles son los deberes que engendra. Su papel es más limitado, más humilde, es simplemente el de sancionar jurídicamente el matrimonio que contraen el varón y la mujer por su voluntad de amarse honestamente por toda la vida. Quienes hacen el matrimonio y definen los deberes son quienes lo contraen. Si ellos quieren unirse de manera limitada, en la forma de una amistad útil y placentera, tendrán una unión soluble y ciertos deberes, y si quieren unirse plenamente, tendrán una unión permanente y otros deberes.

Ante el desprestigio que actualmente va teniendo el matrimonio como consecuencia de su ideologización legislativa, es necesario recuperar su esencia, sobre todo para que los jóvenes descubran en él un camino de plenitud, el ámbito propio donde pueden vivir, en el sentido de dar y recibir, el amor al prójimo como a uno mismo, donde pueden liberarse de la tiranía del yo y alegrarse por su entrega, donde pueden vivir el heroísmo del deber cotidiano y la recompensa de la paz interior. 